\title{
The Pursuit of Happiness: A Calculation of the Hidden Costs of Being Black in the $2 I^{\text {st }}$ Century
}

The Review of Black Political Economy

(C) The Author(s) 2021

(c) (i)

Article reuse guidelines: sagepub.com/journals-permissions DOI: I0.I I77/003464462 | I05583 | journals.sagepub.com/home/rbp

(SAGE

\author{
Joaquin Alfredo Angel Rubalcaba' \\ and Candis Watts Smith ${ }^{2}$
}

\begin{abstract}
There is no shortage of evidence documenting glaring disparities on important socioeconomic and health indicators between White and Black Americans. Persistent racial disparities are the consequence of a historic system of structural racism. Given ongoing inequities in nearly every realm of American life, we aim to calculate the contemporary cost of racial inequity. We contribute to a growing body of literature concerning the "hidden cost" of being Black by employing a novel methodological approach and centering a paradigm of intersectionality (Crenshaw, 1991; Shapiro, 2004). Specifically, we account for the disparities in health and income between Blacks and Whites by using the compensating and equivalent surplus frameworks to calculate willingness to accept (WTA) and willingness to pay (WTP) estimates. We estimate the WTP to avoid the disparity in health, income, and wellbeing between Black and White Americans, to be between approximately $\$ 38,000$ and $\$ 45,000$ per year per person using the Behavioral Risk Factor Surveillance System as well as the General Social Survey, respectively. These estimates can be interpreted as the annual willingness to pay by an average White person to avoid the disparities in income and health experienced by the average Black person.
\end{abstract}

\section{Keywords}

wellbeing, inequity, health, racial disparities, non-market value

\footnotetext{
'Department of Public Policy, University of North Carolina at Chapel Hill, Chapel Hill, NC, USA

${ }^{2}$ Department of Political Science, Duke University, Durham, NC, USA

\section{Corresponding Author:}

Joaquin Alfredo Angel Rubalcaba, University of North Carolina at Chapel Hill, Department of Public Policy, Chapel Hill, NC, USA.

Email: jrubalca@unc.edu
} 


\section{Introduction}

What is the cost of additional stress, worse health, or lower pay for the same work that the average Black person must take on in comparison to her White counterpart? To what extent would a similarly situated White person's subjective wellbeing change if they were Black? What is the monetary value of that change? Insight into this set of questions requires a measure to take into consideration of the ongoing harm from a system of historic (and contemporary) laws, policies, and individual and collective efforts to maintain a racial hierarchy, whereby White Americans dominate (Feagin, 2013; Omi \& Winant, 1994). Specifically, such a measure would capture the loss in wellbeing from disparities between Whites and Blacks that have been documented in health (Acevedo-Garcia et al., 2008; Center on Society \& Health, 2015; Joffe \& Parker, 2012; Tucker et al., 2007), wealth (Eligon \& Gebeloff, 2016; Oliver \& Shapiro, 1995; Zaw et al., 2017), return on investment of education for wages and income (Cohen, 2014; Editorial Board, 2017; Eligon \& Gebeloff, 2016), debt (Cottom, 2017; Seamster, 2019) employment (Bureau of Labor Statistics, 2014; Pager \& Shepherd, 2008), criminal justice outcomes (Alexander, 2010), and even the benefit of the doubt (Pager, 2007; Royster, 2003).

Scholars who are cognizant of these persistent inequalities have worked diligently toward calculating the "hidden costs" of being Black (Johnson \& Sell, 1976; Shapiro, 2004; Siegel, 1965) but determining the costs of anti-Black racism is difficult. Despite the challenge, some scholars have tackled the issue by focusing on the historical legacies of slavery and Jim Crow, particularly as they effect intergenerational wealth accumulation and transfers (or the lack thereof); both systems - slavery and Jim Crow-are at the root of ongoing and persistent racial inequity in the United States (Darity, 2008; Darity \& Frank, 2003). Models that incorporate purloined wages and stolen property from the slavery and antebellum eras produce monetary sums that help Americans wrap their minds around the financial costs of the legacy of racially discriminatory policies in their society. Indeed, a renewed and broadened conversation around reparations to Black Americans requires such calculations (Coates, 2014; Darity \& Mullen, 2020).

We contribute to this intellectual, practical, and policy pursuit, but we approach the question from the standpoint of estimating the contemporary, every day, and mundane costs of being classified as Black in the United States. We overcome some of the basic challenges of calculating the hidden costs of being Black by employing a novel methodological approach and centering a paradigm of intersectionality (Crenshaw, 1991; Shapiro, 2004). Specifically, we estimate the costs of the disparities in health and income between Blacks and Whites across gender by using the compensating and equivalent surplus frameworks. Ultimately, we calculate the willingness to accept (WTA) and willingness to pay (WTP) estimates of experiencing the "downside" of racial inequality. We estimate the WTP to avoid the disparity in health, income, and wellbeing between Black and White Americans, to be between $\$ 38,000$ and $\$ 45,000$ per year per person using the Behavioral Risk Factor Surveillance System as well as the General Social Survey, respectively. An alternative interpretation of this estimate can be said to be the willingness to pay by an average White person to avoid the 
disparities in income and health experienced by the average Black person so as long as inequalities persist.

\section{Racial Inequality in Black \& White}

As mentioned, the United States is a racialized social system (Bonilla-Silva, 1997). Consequently, in nearly every aspect of American life, Whites gain more benefits and people of color experience more disadvantages, on average. These disparities are well-evidenced in the areas of health and income. Black Americans have historically had shorter life expectancy as well as higher rates of chronic diseases, such as diabetes, hypertension, and cardiovascular disease. Black infants are more likely to die in their first year of life than White infants. Researchers who focus on racial disparities find that chronic stress, experiences with racial discrimination, and economic distress produce suboptimal health outcomes (Dressler et al., 2005). Though some attempt to point to issues of diet, Black culture, and individual behavior as explanations for racial disparities in health, experts reveal that structural determinants are more important to consider (Dressler et al., 2005), such as access to quality health care and affordable, healthy foods. Both are in much shorter supply for Black Americans in comparison to Whites (Center on Society and Health 2015; Fitzpatrick \& LaGory, 2002; Hasnain-Wynia et al., 2007). What's more, doctors are systematically likely to under-treat Black patients (Cykert et al., 2010).

Similar patterns exist in the realm of income and wages. To begin, Black unemployment have historically been twice as high as the rate of Whites, even in times when these rates are at historic lows (Lopez Bunyasi \& Smith, 2019a, 2019b). Research shows that Black folks are less likely to get call backs for jobs than Whites, and even formerly incarcerated White men are more likely to receive an interview for a job than Black men with no criminal record (Pager, 2007). What's more, despite the vast changes in anti-discrimination laws as well as transformations in social norms, research shows that between 1980 and 2015, the gap in median wages between Black and White men has largely gone unchanged; researchers also find that Black Americans do not receive the same return on investment from higher education (Patten, 2016).

Relatedly, a paradigm of intersectionality (Crenshaw, 1991, 1989) reveals that Black women face special challenges to their health as well as their income due to overlapping systems of oppression, including racism, sexism and classism. For instance, Black women are more likely to die from pregnancy related complications than White women (Simon, 2016; Tucker et al., 2007). While women, generally speaking, make significantly less than White men, research shows that "on average, Black women in the U.S. are paid 38\% less than White men and $21 \%$ less than White women" (Hegewisch \& Williams-Baron, 2017; Lean In, 2019). Scholars have pointed out that education does not close important gaps for Black women. For example, the Black-White infant mortality gap is greater among the well-educated than those who have less education; in fact, highly educated Black women are more likely to lose a child than low-educated White women (Matthew et al., 2016). 
Attaining education also does not close key financial gaps, such as wealth, for Black women or their families. Indeed, though Black women are much more likely to go to college than Black men, one of the barriers to wealth accumulation for Black women is crushing student debt (Zaw et al., 2017).

These patterns which mark a racialized social system can be found in a wide array of realms of American life. However, we focus on these two aspects of racial inequalityincome and health-because (a) there is a great deal of reliable data that we can analyze, and (b) touching on each of the many inequalities in American society (e.g. residential segregation, school quality, criminal justice, stereotypes, wealth, debt) would balloon the scope of this article given the ubiquity of racial inequality; we simply do not have the space. Consequently, we should note an important caveat: because we only incorporate disparities in health and income in our analysis below, all of our calculations about the hidden costs of being Black are underestimations.

\section{The Cost of Living While Black}

With a full appreciation of the depths and consequences of these persistent inequalities, researchers, public intellectuals, and journalists have made efforts to determine either the costs of living as a Black person in the United States as well as to ascertain the financial costs wrought by the legacies of slavery and/or Jim Crow to Black Americans' current financial well-being and wealth status, or lack thereof. For instance, Ranson and Sutch (1990) estimated that the value of exploited labor of enslaved people between 1806 and 1860 was about $\$ 3.4$ billion, compounded to 1983. Darity (2008), then compounded that sum into 2004 dollars at an annual interest rate of 5 percent and determined the value to be around $\$ 9.12$ billion. Other scholars who have developed alternative calculations based on lost wages and stolen property estimate sums between $\$ 1$ trillion and \$6 trillion dollars (see Darity, 2008 for a review of this literature). Darity (2008) notes that, "none of these approaches incorporate the harms of slavery, the inherently coercive nature of the system, the denial of the ability to accumulate property or acquire education, or the denial of control over one's family life." Consequently, estimates like these are best characterized as underestimations of the value of past injustices. To be sure, present day inequalities that we see in American society are rooted in this history.

Those who are cognitive of these inequities have also noted that White Americans, whose political will is required to make major policy transformation, must first recognize disadvantages that are disproportionately allocated to Blacks as well as the unearned advantages of White privilege in order to buy into this conversation (Dawson \& Popoff, 2004; Mazzocco et al., 2006). With this in mind, some researchers have relied on Whites' calculations of either White privilege or Black disadvantage to estimate the costs of living as a Black person in the United States. To the best of our knowledge there are only two studies that have attempted to assign an economic value to contemporary racial inequalities, and both leverage the contingent valuation method (CVM), widely used and well established in environmental economics, to estimate the economic value of racial disparities. The first study was originally conducted by 
Hacker (1992) and the most recent was conducted by Mazzocco et al. (2006). Simply put, scholars asked White respondents what they would need to be paid to move from the status quo (i.e., being classified as White) to some hypothetical counterfactual (i.e., living as a Black person).

Hacker found that most of his respondents, comprised of a convenience sample of college students, felt it "would not be out of place to ask for \$1 million for each future year they would be living as a Black American" (42). In stark contrast, Mazzocco et al. (2006) relied on a more systematic study of White respondents, who were asked directly for their estimation of the economic value of a change in race from White to Black; on average, the response was below a lifetime amount of $\$ 10,000$. However, this group of scholars also developed a scenario that mimicked the information of racial inequality in the United States; rather than ask about the cost of being Black, directly, they instead inquired about the cost of a shift from majority to minority status in a fictional land called Atria. In this scenario, the median request was around $\$ 1$ million. A charitable reading of the results suggests that Whites severely underestimate the extent to which Black American face inequalities. But, the results of the latter study are not much different from that of Hacker's (1992) and highlights Whites' awareness of the cost of persistent racial inequality. The gap between the requested values across the two experiments in the Mazzocco et al. (2006) study reveals that the CVM approach to estimating the value of racial inequalities is not a suitable approach when framed in the context of a change in race. The estimations will be informed by respondents' knowledge or acknowledgement of racial inequality. Research on an epistemology of ignorance highlights White Americans' aggressive efforts to not know the extent and depths of anti-Black racism and White racial privilege (Mills, 2007; Mueller, 2017).

While we acknowledge the intrinsic value of race and ethnicity, we suggest developing an analysis that centers the instrumental or economic value of racial disparities as measured in health, income, and wellbeing could provide an estimate of the "hidden costs" of being Black in a way that is reliable and replicable, and further, does not pivot on whether or the extent to which respondents understand the ramifications of structural racism. Instead, one can empirically estimate both compensating surplus (CS) and equivalent surplus (ES) for a simultaneous change in health, income, and wellbeing that would hypothetically occur for a change in race. Put simply, CS speaks to the monetary compensation that one would need to provide an individual to make them indifferent to any changes to the status quo. Meanwhile, ES refers to change in one's income that would need to be made in order to make the condition of one's life in a counterfactual situation about the same as it is in the status quo.

We have previously outlined the inequalities that arise in health and income. Scholars of subjective wellbeing provide evidence that measures of subjective wellbeing, such as happiness, are widely considered "valid and reliable [measures] of quality of life, positive affect and mental well-being" (Cummings, 2020, "6"; Yang, 2008; Veenhoven, 1996). Yang notes that measures of subjective wellbeing "are also useful for determining the extent to which societies meet the needs of their members and the degree to which citizens thrive" (Yang, 2008, p. 204). Relatedly, 
stratification scholars suggest that differences in subjective wellbeing across racial groups captures aspects of structural inequalities, noting that the persistent "racial disparity in quality of life...strongly suggested that lingering social and economic disadvantages exerted a powerful negative effect on the subjective well-being of African Americans" (Hughes \& Thomas, 1998, p. 786). Additionally, fluctuations in wellbeing across populations have been linked with major social, political, and economic transformations in society, such as historic elections or economic recessions (Cummings, 2020; Malat et al., 2011). Taken together, we can leverage measures that are reliable and valid, such as subjective wellbeing, as well as objective measures, such as income to estimate the non-market valuation of the hidden costs of experiencing racial inequality.

\section{Theoretical Framework}

In order to ascertain estimates of the economic value of racial disparities between White and Black Americans, we rely on a theoretical grounding developed within welfare economics (Hausman, 1981; Hicks, 1943; Lankford, 1988; Willig, 1976). Specifically, we estimate compensating surplus (CS) and equivalent surplus (ES), opposed to compensating variation (CV) and equivalent variation (EV), as the preferred measures of a change in welfare given the constrained nature of race and health (Freeman, 2003; Lankford, 1988). In the context of this study, CS represents the pecuniary compensation needed to make the average White American indifferent to being subjected to the inequalities experienced by the average the Black American. Alternatively, the ES measure represents the change in income needed to make the average White American, without being subjected to the inequalities experienced by the average the Black American, no better off or worse off than the average Black American.

Throughout our models, both theoretical and empirical, we assume that being White, as a race state, is the status quo from which we measure the change in welfare. This positioning of the status quo anchors our $C S_{w \rightarrow b}$ and $E S_{w \rightarrow b}$ measures to estimate the economic value of racial inequality as though White Americans were being asked the value they would place on being subjected to the inequalities experienced by Black Americans. Note that we consider the alternative $\left(C S_{b \rightarrow w}\right.$ and $\left.E S_{b \rightarrow w}\right)$ in the appendix. Positioning the status quo on being Black implies an economic value that would be akin to asking Black Americans how much they would pay to experience White privilege. Given the exhaustive evidence that has documented lower health outcomes and incomes among Black Americans relative to White Americans, we assume that a hypothetical change in race, from White to Black, is welfare decreasing in terms of health and income. This assumption implies a specific interpretation of $C S_{w \rightarrow b}$ and $E S_{w \rightarrow b}$. The $C S_{w \rightarrow b}$ implies a right to the status quo, the position of being an average White American, and therefore elicits the minimum willingness-to-accept (WTA) compensation to be subjected to the inequalities imposed on Black Americans. The $E S_{w \rightarrow b}$ implies the right to the change in state, a change from White to Black, and therefore elicits the maximum willingness-to-pay (WTP) to avoid the inequalities experienced 
by the average Black American. The distinction between the two measures is important to note because CS and ES have opposing implications on property rights - a right to the inequality or a right to the status quo, respectively. ${ }^{1}$ Additionally, WTP measures are bounded above by income while WTA measures are not.

We begin an outline of the CS and ES measures with a simple model of indirect utility. The indirect utility function for any given individual is explained here as $u(m, q)$, where $m$ is the expenditure on the numeraire good and $q$ is health quality. It is implied that the indirect utility function represents utility as a function of the optimal level of consumption of the numeraire good subject to a budget constraint, where the individual takes the level of health quality $(q)$ as given. Our treatment of race in the model assumes race is exogenous and only influences the levels of expenditure and health quality. For instance, the indirect utility function expressed as $u\left(m_{w}, q_{w}\right)$ represents the maximum utility as a function of the state of being White, as indicated by the subscript $w$. Similarly, $u\left(m_{b}, q_{b}\right)$ represents the maximum utility as a function of the state of being black, as indicated by the subscript $b$. A hypothetical change in race is considered exogenous, and individuals are assumed to optimize given the new race state. Both CS and ES are used to measure welfare given a hypothetical change in one's state as determined by race. To make this point explicit, consider the following equation:

$$
u_{w} \equiv u\left(m_{w}, q_{w}\right)=u\left(m_{b}-C S_{w \rightarrow b}, q_{b}\right)
$$

Equation (1) positions the state of being White $\left(u_{w}\right)$ as the status quo, and in order to satisfy the condition $u_{b}$ needs to be adjusted by $C S_{w \rightarrow b}$. Solving Equation (1) for $C S_{w \rightarrow b}$ measures the minimum amount of compensation an individual would need to be indifferent to a change in race from White to Black, or the WTA.

$$
u_{b} \equiv u\left(m_{w}+E S_{w \rightarrow b}, q_{w}\right)=u\left(m_{b}, q_{b}\right)
$$

Equation (2) also positions the state of being White $\left(u_{w}\right)$ as the status quo. However, now the individual has an obligation, or implied right, to the change in race, and in order to satisfy the condition $u_{w}$ needs to be adjusted by $E S_{w \rightarrow b}$. Solving Equation (2) for $E S_{w \rightarrow b}$ measures the maximum change in income needed to make the state of being White $\left[u_{w} \equiv u\left(m_{w}, q_{w}\right)\right]$ no different than the state of being black $\left[u_{b} \equiv u\left(m_{b}, q_{b}\right)\right]$, or the WTP to avoid the change in race.

\section{Empirical Strategy}

The empirical strategy we use to estimate CS and ES is built on a non-market valuation technique which leverages subjective measures of wellbeing (Benjamin et al., 2014; Ferrer-i-Carbonell \& van Praag, 2002; Finkelstein et al., 2013; Levinson, 2012; Luechinger, 2009; Perez-Truglia, 2015; Welsch, 2007). The subjective measure of wellbeing (SWB) empirical approach uses wellbeing survey instruments, such as life satisfaction or happiness, as a proxy for utility to estimate the marginal and inframarginal WTP for non-market goods such as environmental and health quality. To the best 
of our knowledge this study is the first to extend the SWB method to measure the economic value of racial disparities. Appropriately, we examine the validity and the robustness of our results in later sections.

While much of the applications of the SWB method estimates the marginal willingness to pay (MWTP), we base the SWB approach on the infra-marginal changes in welfare. Drawing on the framework discussed in the previous section, we model the SWB function as $S=u(m, q)+\varepsilon$, where the SWB measure $(S)$ is a function of the indirect utility function and the error term $\varepsilon$. Additionally, we assume the SWB measure to be cardinal and interpersonally comparable and therefore allows us to treat the dependent variable as continuous (Ferrer-i-Carbonell \& Frijters, 2004). One empirical limitation of the SWB method is its sensitivity to attenuation bias, attributable to income. The prevailing solution is to instrument, as thoroughly explored by Powdthavee (2010) and is a strategy we apply in this study. Specifically, the first-stage equation of our model uses education attainment, $Z_{i}$, as an instrument for the natural $\log$ of income, $\ln \left(m_{i}\right)$, in the first stage. See the appendix for a discussion and empirical investigation into the validity of our instrumental variable approach.

$$
S_{i}=\alpha \ln \left(m_{i}\right)+\lambda q_{i}+\sum_{j=1}^{n} \rho_{j} R_{j i}+\sum_{j=1}^{n-1} \varphi_{j} Q_{j i}+\mathrm{X} \beta+\varepsilon_{i}
$$

Equation (3) illustrates the empirical estimate of the SWB function and represents the second-stage equation. For individual $i$, self-reported level of SWB, $S_{i}$, is regressed on the natural $\log$ of income or expenditure, $m_{i}$, self-reported health quality, $q_{i}$. For individual $i$, in racial group $j$, a set of race indicator variables, $R_{j i}$, indicators for the interaction between race and health quality variables, $Q_{j i}$, and a vector of individual specific characteristics are included. Note that in Equation (3) there are $n$ number of racial categories accounted for by the race indicator variables, $R_{j i}$. Given that we do not exclude a category, traditionally the base comparison group, we omit the intercept to avoid perfect multicollinearity. As a result, each of the $n$ race categories are represented in the model as the race specific intercept (Greene \& Seaks, 1991; Suits, 1984). This approach is applied to make the connection between the empirical and theoretical models tractable and for ease of interpretation. While this technique is not widely represented in the literature, the model is identical to a model that applies the conventional approach of incorporating categorical variables (Greene, 2012, p. 152; Greene \& Seaks, 1991; Suits, 1984). Additionally, the health quality variable is treated as a continuous variable in the regression. ${ }^{2}$

\section{Evaluating CS and ES}

The estimates from the SWB and expenditure functions, Equation (3), are used to calculate $C S_{w \rightarrow b}$ and $E S_{w \rightarrow b}$. Given that a change in race is unattainable in reality and thus impossible to observe empirically, we assume that a change in race is hypothetical and is taken over the average for each race state. For instance, a hypothetical change from White to Black results in a change in race specific income and health quality, our 
primary measures of racial inequality, where all other characteristics are inconsequential in the calculation of $C S_{w \rightarrow b}$ and $E S_{w \rightarrow b}$. We derive the $C S_{w \rightarrow b}$ and $E S_{w \rightarrow b}$ welfare measures, in terms of the SWB function as: ${ }^{3}$

$$
\begin{aligned}
& C S_{w \rightarrow b}=m_{b}-m_{w} \cdot e^{\frac{\left(\rho_{w}-\rho_{b}\right)-\varphi_{b} Q_{b}}{\alpha}} \\
& E S_{w \rightarrow b}=m_{b} \cdot e^{\frac{\left(\rho_{b}-\rho_{w}\right)+\varphi_{b} Q_{b}}{\alpha}}-m_{w}
\end{aligned}
$$

The subscripts for the individual in Equations (4) and (5) are removed given that our focus is on the race specific attributes and thus race independent characteristics $(\mathrm{X} \beta)$ are cancelled out when solving for $C S_{w \rightarrow b}$ or $E S_{w \rightarrow b}$.

To facilitate an unambiguous interpretation of our results, it is important to be aware that the model, both theoretical and empirical, produce an ex-post estimation of a pecuniary payment one would be willing to pay to avoid, or the compensation necessary to induce one to accept, a hypothetical change in race - specifically, the implication of race on income and health. The $C S_{w \rightarrow b}$ or $E S_{w \rightarrow b}$ estimates should not be interpreted as the per person amount needed to completely close the health disparities between Black and White Americans. Appropriately, our empirical approach captures the monetary equivalent of a change in race as an exogenous determinant of income and health quality. We estimate the non-market value of racial inequalities that are measured at the group level and thus are far removed for the realm of causality. Nonetheless, our approach provides a practical and unique insight into racial inequality that exists between White and Black Americans.

\section{Data Description}

The primary data used in the analysis include repeated cross-sections of the Behavioral Risk Factor Surveillance System (BRFSS) data series between 2006 through 2017. The BRFSS data series is conducted by the Center for Disease Control and Prevention (CDC) and is designed to be a nationally representative health-related survey of the American population. The sample includes only Black and White respondents between the ages of 18 and 65 who reside in the United States $(n=1,197,483)$, and excludes all respondents who reside in Puerto Rico, Guam, and the Virgin Islands. Individuals categorized as White include all non-Hispanic White respondents $(n=1,083,094)$, while individuals categorized Black included all non-Hispanic Black respondents $(n=114,389)^{4}$

The SWB measure in the BRFSS is measured as an indicator of life satisfaction. As a result, life satisfaction is used in the empirical model as the dependent variable for the SWB function. The life satisfaction survey instrument asks respondents: "In general, how satisfied are you with your life?" Respondents are given a Likert scale type response choice, which is described as: "Very satisfied," "Satisfied," "Dissatisfied," "Very dissatisfied." Health quality is surveyed in a similar fashion, where individual health quality is self-reported and is based on a 5-point scale. The BRFSS asks respondents "Would you say that in general your health is: Excellent, Very good, 
Table I. Survey Instruments Description (BRFSS and GSS).

Behavioral Risk Factor Surveillance System (BRFSS)

\begin{tabular}{ll}
\hline Life Satisfaction & Health Quality \\
\hline $\begin{array}{l}\text { "In general, how satisfied are you } \\
\text { with your life?" }\end{array}$ & "Would you say that in general your health is": \\
I = Very dissatisfied & $\mathrm{I}=$ Poor \\
$2=$ Dissatisfied & $2=$ Fair \\
$3=$ Satisfied & $3=$ Good \\
$4=$ Very satisfied & $4=$ Very good \\
& $5=$ Excellent \\
General Social Survey (GSS) & \\
\hline Happiness & Health Quality \\
\hline "Taken all together, how would & "Would you say your own health, in \\
you say things are these days - & $\quad$ general, is": \\
would you say that you are": & I = Poor \\
I = Not too happy & $2=$ Fair \\
$2=$ Pretty happy & $3=$ Good \\
$3=$ Very happy & $4=$ Excellent \\
\end{tabular}

Good, Fair, Poor." In our analysis, the values for life satisfaction and the health quality variables are ordered from worst the best. For instance, the life satisfaction variable is expressed numerically as one (LifeSatisfaction $=1$ ) for respondents who reported to be "Very dissatisfied" and four (LifeSatisfaction $=4$ ) when "Very satisfied." The life satisfaction and health quality survey instruments, as well as the variable coding, are outlined in Table 1.

Income, in the BRFSS, is recorded at the household level and is explained by 8 categories. We address the income categories by setting income to the midpoint between the lowest and highest value characterized in each category (Hout, 2004). Given that there are a small number of income categories, we regress the midpoint household income variable on age, age squared, education, and gender then fit the model for each individual within the bounds of each household income category.

\section{Summary Statistics}

The descriptive statistics for the BRFSS sample are shown in Table 2. Each of the estimates are cut across race and ethnicity and are compared to the estimates for Whites. Given the design of the empirical model, life satisfaction and health quality are evaluated in detail. The estimates reported in Table 2 shows that Black respondents, on average, reported lower life satisfaction than that of Whites by 0.15 on a 4-point scale. An evaluation of each life satisfaction category reveals the 


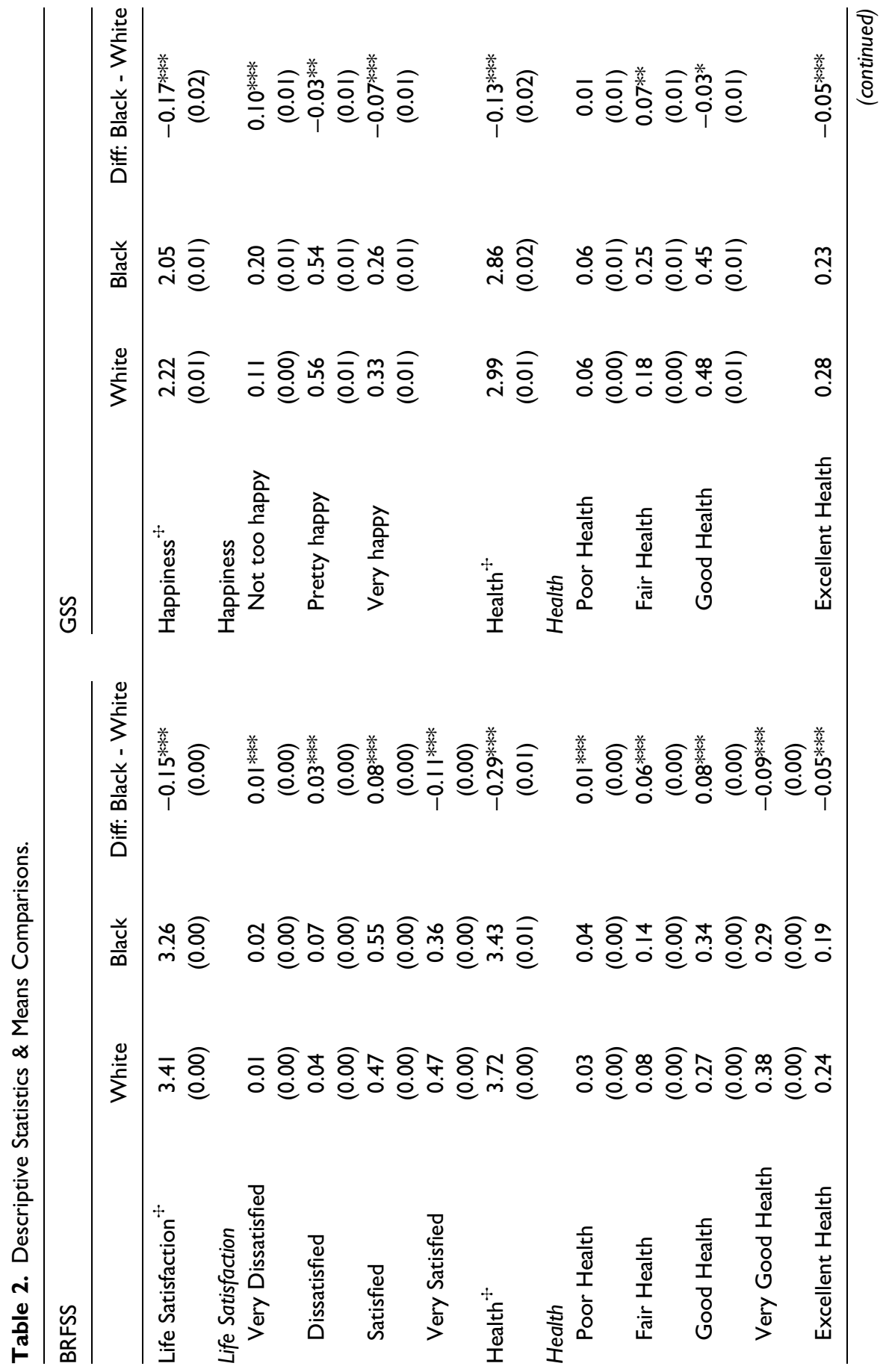




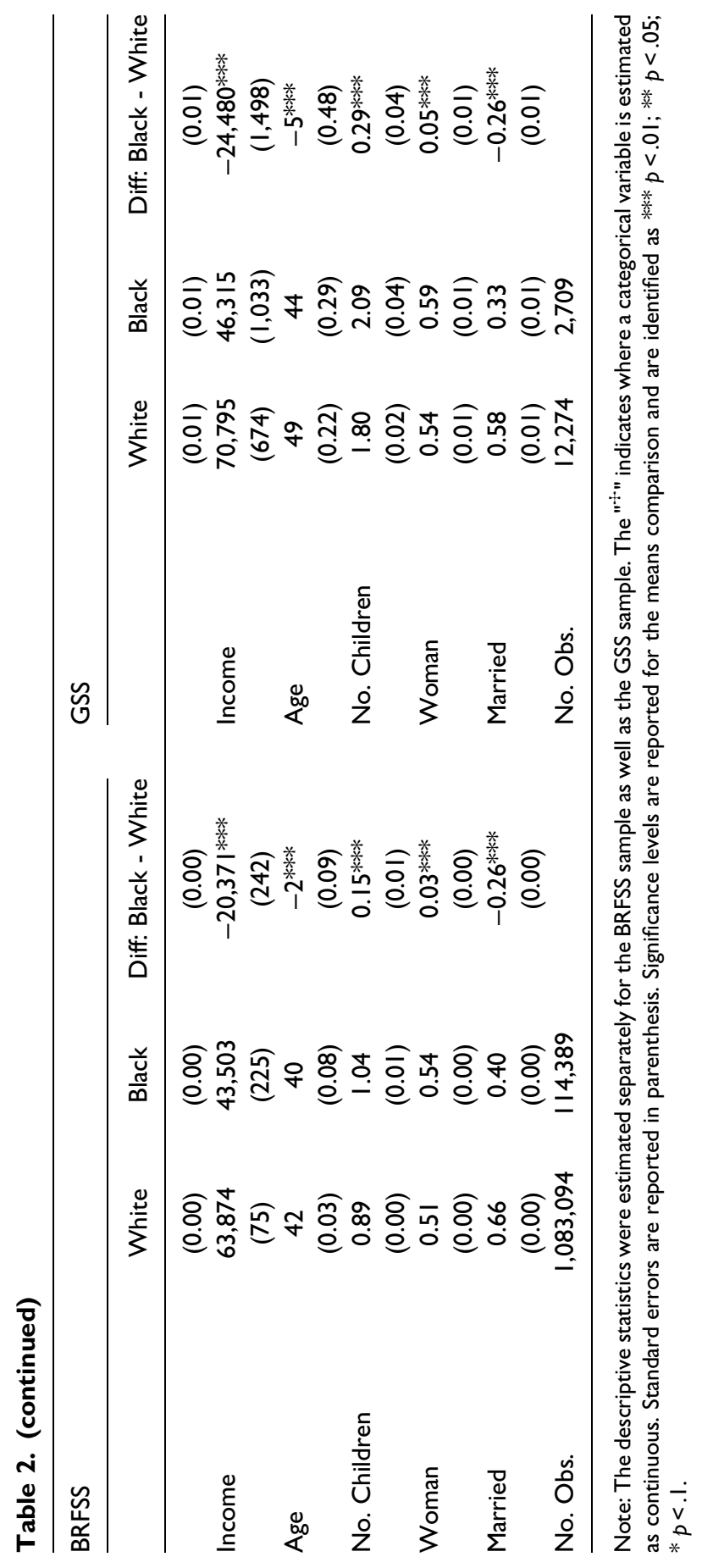


largest Black - White differences are measured in the "satisfied" and "very satisfied" categories. While White respondents reported being "very satisfied" at a greater rate, a difference of 11-percentage points, Black respondents reported being "satisfied" at a greater rate, a difference of 8-percentage points.

A comparison of self-reported health quality between Black and White respondents reveals a similar pattern. White respondents, on average, reported higher levels of health quality by approximately 0.3 on a 5-point scale. The percentage of White respondents who reported "very good health" and "excellent health" is approximately 9-percentage points and 5-percentage points higher, respectively, than that of Black respondents. Alternatively, the percentage of Black respondents who reported "fair health" and "good health" is approximately 6-percentage points and 8-percentage points higher, respectively, than that of White respondents. The disparity in selfreported health quality measured in the BRFSS may be driven by systematic differences in how members of each racial group perceive their health quality, or it may be attributable to a systematic race specific measurement error. This argument also applies to the disparities observed in life satisfaction. However, given extensive empirical evidence reported throughout the health literature, the racial health disparities that we measure in BRFSS are likely representative of more objective measures of racial health disparities, if not an underrepresentation, as previously discussed (also see Williams and Mohammed, 2009).

Household income estimated in the BRFSS reflects the household income inequality, as an indicator economic disparity, reported between White and Black Americans. U.S. Census data shows that in 2016 the median income among White households was approximately $\$ 65,000$ while the median income among Black households was approximately $\$ 40,000$, a difference of $\$ 25,000$ (Chetty et al., 2018). The difference in annual household income between White and Black BRFSS respondents is estimated to be approximately $\$ 20,000$. The similarity between the BRFSS and the U.S. Census household income estimates, across race, suggests our sample closely measures the income and economic inequalities experienced by Black Americans.

Considering the disparities in reported health quality and household income, it is likely that the estimated differences in life satisfaction between White and Black respondents is not asymptomatic or a statistical artifact. Rather, the relatively lower life satisfaction among Black BRFSS respondents, as a representative sample of Black Americans, is likely an expression of experienced health, economic, and other inequalities and injustices - ultimately, an inequality in overall wellbeing (Hughes $\&$ Thomas, 1998). Empirical evidence supporting this notion would be revealed if differences in the levels of life satisfaction reported by White and Black respondents are explained away when racial inequalities are accounted for in the empirical model. Or in other words, levels of subjective well-being ought to be equivalent when systematic inequalities are accounted for; if not, this would suggest that there are, perhaps, some inherent differences between the racial groups' outlook on life. Given the fact that race is socially constructed, the latter proposition is unlikely to be supported empirically. 


\section{Results}

\section{The Value of Racial Disparities}

We begin our analysis with a basic OLS characterization of Equation (3) using the BRFSS sample. The results from the OLS estimation are presented in Column 1 of Table 3, along with the corresponding $C S_{w \rightarrow b}$ and $E S_{w \rightarrow b}$ calculations. The results presented in Column 1 reveal a WTA $\left(C S_{w \rightarrow b}\right)$ of approximately $\$ 236,000$ while WTP $\left(E S_{w \rightarrow b}\right)$ is $\$ 48,000$. Note that that $C S_{w \rightarrow b}$ and $E S_{w \rightarrow b}$ are both negative indicating that a hypothetical change from White to Black would result in a welfare loss. Given the nonlinearity of $C S_{w \rightarrow b}$ and $E S_{w \rightarrow b}$ equations, the standard errors for these welfare measures presented in throughout this study were estimated using the delta method (see Daly et al., 2012).

Results from the 2SLS estimation of the BRFSS sample are presented Column 2 of Table 3. A weak identification test of the instrument was conducted using the Kleibergen and Paap (2006) $r k$ statistic and is reported in the table. The estimates from the instrumental variable approach shows that $C S_{w \rightarrow b}$ (WTA) is approximately $\$ 98,000$; while $E S_{w \rightarrow b}$ (WTP) is approximately $\$ 38,000$. That is, the average White American is willing to accept $\$ 98,000$ in compensation to be subjected to the health and income inequalities experienced by the average Black American, each year the inequality persists. The same average White American would be willing to pay $\$ 38,000$ to avoid the health and income inequalities experienced by the average Black American, each year the inequality persists. It is important to note that the White and Black intercepts, in both the OLS and 2SLS models, are virtually indistinguishable. Also, taking into consideration the differences in average income between Black and White respondents we determine that approximately $\$ 18,000$ of the $E S_{w \rightarrow b}$ (WTP) estimate is attributable to the Black-White health disparity as measured using self-reported health quality.

\section{Validity and Robustness}

To assess the robustness and validity of our estimates, we begin our assessment by reevaluating our models using data from the General Social Survey (GSS). The GSS is a biennial survey that is designed to be representative of American sociological and attitudinal trends (NORC). The GSS sample, used in this assessment, consists of 8,148 Black and White respondents spanning seven biennial cross-sections between 2006 and 2018. Individuals categorized as White include all non-Hispanic White respondents $(n=12,274)$, while individuals categorized as Black include all non-Hispanic Black respondents $(n=2,709)$. The data provides all of the variables used in our analysis of the BRFSS. However, SWB is measured in terms of a 3-point happiness scale in the GSS. Specifically, the happiness survey instrument asks respondents: "Taken all together, how would you say things are these days would you say that you are very happy, pretty happy, or not too happy." Additionally, health quality is measured on a 4-point scale where the GSS survey 


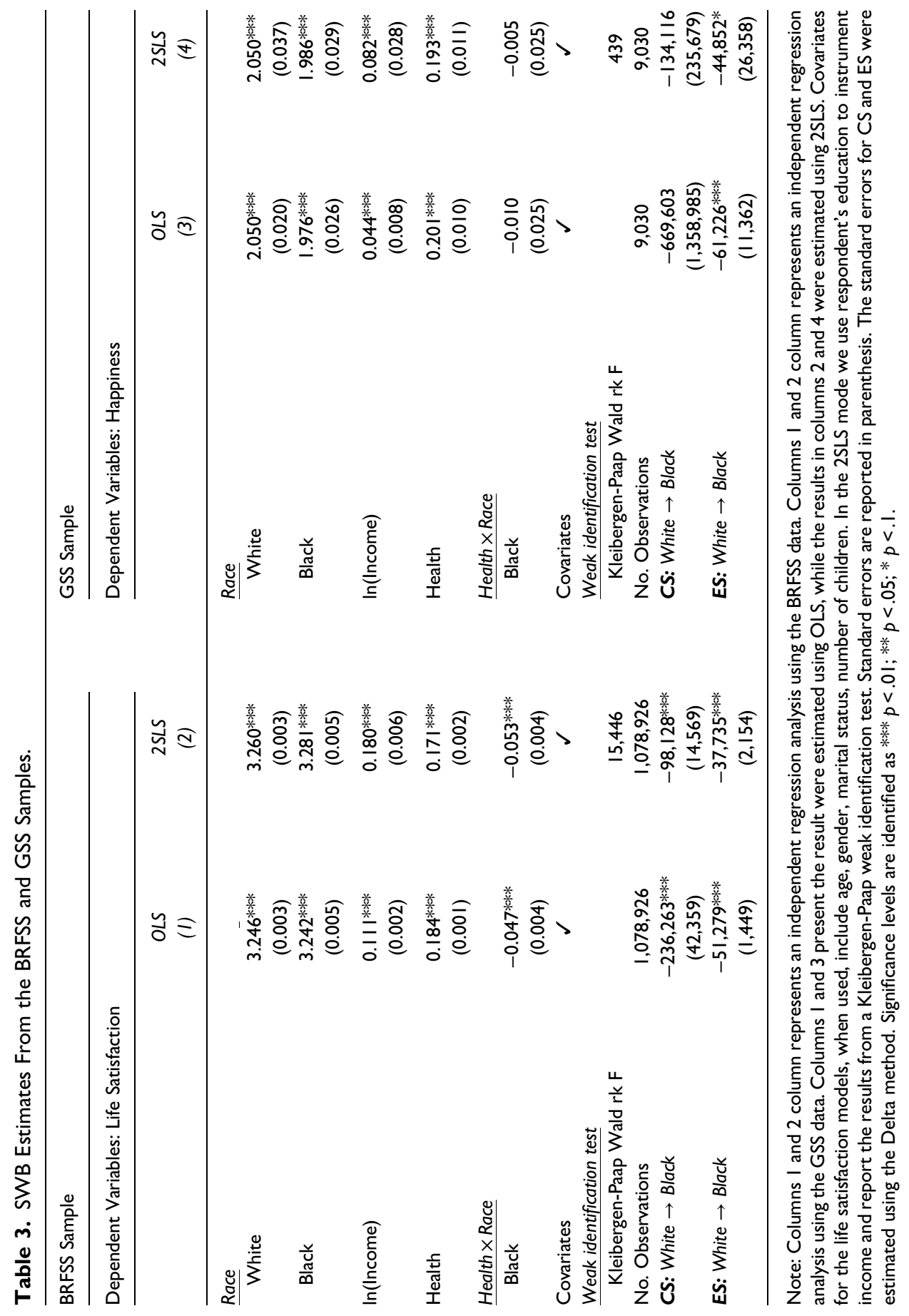


instrument asks respondents: "Would you say your own health, in general, is excellent, good, fair, or poor?" Both the happiness and health quality variables are coded in order from worst to best, see Table 1 for the exact description. The descriptive statistics for the GSS sample are presented in Table 2. While the scaling and context of the SWB measure represented in GSS is different from that in the BRFSS, there are similarities. Specifically, Black respondents on average report lower levels of wellbeing, health quality, and income.

We re-evaluate the OLS and 2SLS models using the GSS sample and present the results in Table 3, where each model is appropriately labeled in column 3 and 4. The results from OLS model suggests a WTP $\left(E S_{w \rightarrow b}\right)$ estimate of approximately $\$ 61,000$, and the results from 2SLS model suggests a WTP $\left(E S_{w \rightarrow b}\right)$ estimate of approximately $\$ 45,000$. The GSS estimates, however, fail to produce statistically significant WTA $\left(C S_{w \rightarrow b}\right)$ estimates in both OLS and 2SLS analyses. While the absence of statistical significance for WTA is cause for concern, the lack of convergence in WTA estimates between the GSS and BRFSS suggests that the SWB approach to nonmarket valuation may not be a valid measure of WTA. Throughout the contingent valuation literature, the disparity between WTP and WTA estimates has been ascribed to disparate psychological perceptions of loss over gains (Chapman et al., 2017; Coursey et al., 1987; Kahneman \& Tversky, 1979). The SWB approach is not rooted in individual perception of loss or gain, which may narrow the scope of the SWB framework. To the best of our knowledge this is the first study to consider both WTP and WTA measures within the SWB approach to non-market valuation.

In Table 4, we display the WTP $\left(E S_{w \rightarrow b}\right)$ values from OLS and 2SLS estimates of the BRFSS and the GSS Samples. We exclude the WTA $\left(C S_{w \rightarrow b}\right)$ given the lack of reliability in its estimation from the GSS. The differences in the WTP estimates were evaluated against $H_{0}: E S_{w \rightarrow b}^{B R F S S}-E S_{w \rightarrow b}^{G S S}=0$, using a two-sample t-test. Ultimately, we fail to reject the null hypothesis suggesting that the differences in WTP $\left(E S_{w \rightarrow b}\right)$, estimated from OLS and 2SLS, were not statistically different. The

Table 4. Evaluation of ES (WTP) Estimates Between GSS and BRFSS.

\begin{tabular}{cll}
\hline & \multicolumn{1}{c}{ OLS } & \multicolumn{1}{c}{2 SLS } \\
\hline BRFSS & & \\
ES: White $\rightarrow$ Black & $-51,279 * * *$ & $-37,735 * * *$ \\
& $(1,449)$ & $(2,154)$ \\
GSS & & \\
ES: White $\rightarrow$ Black & $-61,226 * * *$ & $-44,852^{*}$ \\
Differences in ES & $(11,362)$ & $(26,358)$ \\
& 9,946 & 7,117 \\
& $(16,664)$ & $(26,446)$ \\
\hline
\end{tabular}

Note: The standard errors estimated from the Delta method were also reported in Table 3. The difference in ES estimates were evaluated using a two-sample t-test, where the null-hypothesis is a difference of zero. All Standard errors are reported in parenthesis. Significance levels are identified as $* * * p<.01 ; * * p<.05 ; * p<$.I. 
difference in the WTP $\left(E S_{w \rightarrow b}\right)$ estimates between the BRFSS and GSS sample using the OLS and 2SLS estimates is approximately $\$ 10,000$ and $\$ 7,000$, respectively. We read the magnitude of these differences as an acceptable tolerance in imprecision given the independent survey designs and differences in SWB, health quality and income measures between the BRFSS and GSS. The evaluation and the converging results across surveys supports the construct validity of our primary findings.

\section{An Intersectional Analysis}

Our final analysis investigates the economic value of inequalities at the intersection of race and gender. To account for the intersectionality of race and gender, we split the sample across gender then across race. The results from the intersectional analysis are presented in Table 5. The first two models, presented in the "Men" and "Women" columns, investigate the economic value of racial inequalities across gender. Here we use the 2SLS estimation using the BRFSS sample restricted by gender. Results from the sample of men suggests that the WTP $\left(E S_{w \rightarrow b}\right)$, for an average White American man, to avoid the health and income inequalities experienced by the average Black American man is approximately $\$ 33,000$ for each year the inequalities persist. Results from the sample of women suggests the WTP $\left(E S_{w \rightarrow b}\right)$, for an average White American woman, to avoid the health and income inequalities experienced by the average Black American woman is approximately $\$ 41,000$ for each year the inequalities persist. The disparity in WTP $\left(E S_{w \rightarrow b}\right)$ estimates between men and women is approximately $\$ 12,000$, suggesting that White women are willing to pay more than White men to avoid the inequalities imposed on Black Americans in their respective gender groups.

The subsequent analysis restricts the BRFSS sample by race and models the inequalities experienced across gender. The results from the analysis across race are also presented in "White" and "Black" columns of Table 5. In this analysis, gender is modeled in the same manner as race was in previous model. For instance, we include both gender groups into the SWB function to represent the gender specific intercepts. $C S_{w \rightarrow b}$ and $E S_{w \rightarrow b}$ estimates for each race specific sample are not statistically significant. Interestingly, we find that $C S_{\mathrm{Men} \rightarrow \text { Women }}$ (WTP) to be approximately $\$ 7,000$, while $E S_{\text {Men } \rightarrow \text { Women }}$ (WTA) $\$ 8,000$. Notice the change in interpretation for these welfare measures. The adjustment to interpretation is driven by the change in the sign of $C S_{\text {Men } \rightarrow \text { Women }}$ and $E S_{\text {Men } \rightarrow \text { Women, suggesting a welfare increase among }}$ White respondents for a hypothetical change between from the average White man to the average White woman - a finding that loosely corroborates findings from other studies (e.g. Yang, 2008). In contrast, a hypothetical change in gender from a woman to a man among Black Americans, while not statistically significant, is welfare decreasing. Scholars like Kimberlé Crenshaw note that mainstream narratives of racial inequality tend to focus on Black men (Crenshaw, 2006). This sentiment is corroborated by political scientist Cathy Cohen, who notes that the political and policy issues that are prioritized even within a racial group-consensus issues"tend to be associated with those who are the top rung of that group (e.g. male, 


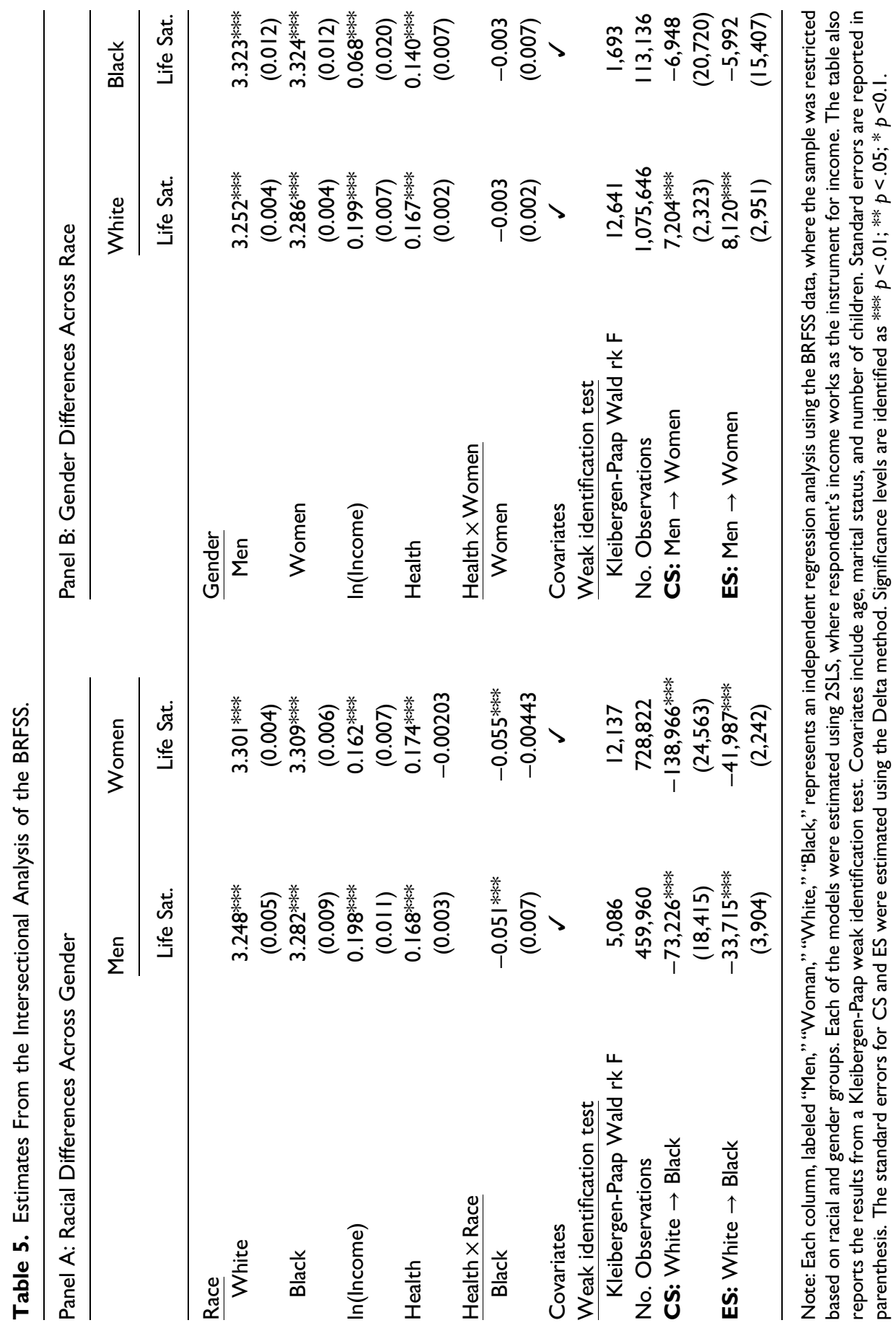


heterosexual, able-bodied) (Cohen, 1999, see also, Lopez Bunyasi \& Smith, 2019a, 2019 b). As such, on the surface this particular finding may be counterintuitive to most, but it is not for scholars of intersectionality.

\section{Discussion}

Scholars have provided a great deal of evidence relating to the existence of racial inequality across various realms of American life. But what is the everyday cost of living as a Black person in the U.S.? What is the cost of living in a less healthy body? What are the costs of having lower levels of happiness and wellbeing due to experiences with racism? Or lower wages due, in part, to racial discrimination? One way that scholars have attempted to determine the financial costs of racial inequity is to calculate the value of lost or stolen wealth, or to establish the cost of closing the racial wealth gap (Darity, 2008; Darity \& Frank, 2003; Ranson \& Sutch, 1990; Shapiro, 2004). Other scholars have relied on White Americans' perceptions and evaluations of racism to estimate these costs of racial inequality. Our study is the first study to rely on largen, nationally representative data and measures of well-being to assess the non-market valuation of racial inequality on health and income. Using data from the BRFSS as well as the GSS and models that allow us to disentangle racial disparities from a subjective well-being function, we are able to approximate compensating and equivalent surplus values for a change in health, income, and wellbeing that would hypothetically occur with a change in race-from White to Black.

The equivalent surplus (ES) value we calculate corresponds to the maximum willingness-to-pay (WTP) to avoid the inequalities. Here, we estimate the WTP to be approximately $\$ 38,000$ ranging within a 95\% confidence interval between $\$ 33,000$ and $\$ 42,000$. What's more, these welfare estimates were similar in value between two independently collected surveys - providing validating evidence of our primary results. It should be noted that the WTP estimates are bounded by one's income. In contrast to a WTA scenario, whereby somebody has asked you how much they would have to pay you to move from the status quo condition to another, WTP asks how much you are willing to pay to avoid shifting from the status quo. The median income of White Americans in the BRFSS sample is about $\$ 65,000$. Essentially, the WTP estimate here suggests that White Americans would pay between $51 \%$ and $64 \%$ of their income to avoid the health and income inequalities that the average Black American lives through on a day-to-day basis. While the income disparity between White and Black respondents $(\approx 20,000)$ is a one-for-one value, the pecuniary value of the health disparity is approximately $\$ 18,000$ or between $20 \%$ and $33 \%$ of the total income among the average White American.

Scholars theorize that WTP and WTA values should be about the same in a condition where the shift from the status quo to another state is about the same (Hanemann, 1991; Shogren et al., 1994). For example, these two values should be about the same if we offer a Kit-Kat rather than a Reece's Peanut butter cup; one is a decent substitute for the other. But these two values are have been shown empirically to be quite different in a condition whereby the status quo cannot be easily duplicated, or when there no close 
substitutes found in the market (Chapman et al., 2017; Coursey et al., 1987; Kahneman \& Tversky, 1979). Though we did not consistently find statistically significant values for WTA measures $\left(C S_{w \rightarrow b}\right)$, it should be noted that when we did, the values were in some cases were more than double the average income-perhaps, speaking to the unique and incomparable value of White privilege (McIntosh, 1998 [1989]).

In addition to questions around racial inequality, our analyses also speak to the overlapping and intersecting costs of racial inequality and sexism. Though limited in scope, our analysis highlights the differential experiences Black women and Black men have from their White counterparts. To reiterate, the WTP estimates of shifting from a White person to a Black person across genders range from $\$ 34,000$ (male shift) to $\$ 42,000$ (female shift). And though the differences in shifting across gender among Black respondents aren't significant, the findings suggest (a) race is a key lens through which gender (and life, generally speaking) is lived, and (b) all groups would be willing to pay something to avoid being a Black woman.

We should be clear about what these findings do not tell us. First, they do not suggest that being Black is valued less by Black Americans. In fact, our results reveal that when various inequities are accounted for in our models, Blacks' scores of subjective well-being are very similar to that of Whites. Consequently, our estimates reveal not the value of being White or Black, per se, but instead the value of living through systematic inequalities in health and income. Should these inequalities disappear, we predict that we would find ES and CS values that are statistically insignificant; in fact, we did find this (Model 5, Table 3). Our estimates, then, are best understood as the willingness to pay by an average White person to avoid the disparities in income and health experienced by an average black person so as long as inequalities persist.

Although our method serves as a substantial improvement over the contingent evaluation method used in previous studies, we should reiterate a major caveat: all of the above estimates are very likely to be underestimations on at least two levels. First, what our results reveal is the costs that come from living with systematically fewer wages, lower quality health, and lower overall quality of life. Our models do not include inequalities that are manifested in wealth (Hamilton et al., 2015), quality of or access to education (Hannah-Jones, 2014), racialized debt (Seamster, 2019), and the like. It is likely that inclusion of additional factors such as the aforementioned would increase both ES and CS values. Second, research suggests that a one dollar increase income does not equate to a proportional change in health quality for Blacks as it does for Whites; or in other words, money has a greater impact on the health of Whites relative to Blacks. An excellent example of this is illustrated by the data that reveals that Black women with relatively high incomes and levels of education still suffer greater levels of infant mortality than low-income White women (Matthew et al., 2016).

In 1989, John Conyers introduced H.R. 40, a bill that calls for the study of reparations to Black Americans and did so every year for nearly three decades to no avail. ${ }^{5}$ Meanwhile, stratification economists have been working for just as long to highlight the so-called hidden costs of racism in effort to justify reparations to Black Americans. Despite the detailed and nuanced analyses put forward by some of the 
U.S.'s most acclaimed scholars concerning the legacy of legalized inequality, structural racism, and race-gendered violence in this country, a conversation around redress and reparations has only recently come to the attention of a broader proportion of Americans-perhaps, due to the most recent Black freedom movement's efforts to resist and transform the national narrative of inevitable and consistent racial progress (Lebron, 2017; Taylor, 2016). Arguments against reparations are often rooted in aggressive unwillingness to acknowledge inequality that arises from systemic racism meanwhile other detractors note that we simply do not know or cannot quantify the on-going costs of racial inequality. The analyses in this paper serves to weaken both arguments.

\section{Declaration of Conflicting Interests}

The author(s) declared no potential conflicts of interest with respect to the research, authorship, and/or publication of this article.

\section{Funding}

The author(s) received no financial support for the research, authorship and/or publication of this article.

\section{ORCID iD}

Joaquin Alfredo Angel Rubalcaba (D) https://orcid.org/0000-0001-6159-9414

\section{Notes}

1. Given that both CS and ES can be interpreted as a measure of WTA and WTP, depending on the change in quality or state, we proved a concise guide for interpretation following the work by Freeman (2003).

\begin{tabular}{lll}
\hline Measure of Welfare & Quality Increase & Quality Decrease \\
\hline $\begin{array}{l}\text { ES: Implied right to the } \\
\text { change in quality }\end{array}$ & WTA to forgo the change & WTP to avoid the change \\
$\begin{array}{l}\text { CS: Implied right to the } \\
\text { status quo }\end{array}$ & WTP to attain the change & $\begin{array}{c}\text { WTA to be subjected to } \\
\text { the change }\end{array}$ \\
\hline
\end{tabular}

2. As shown in Table 1, the health quality survey items are recorded as an ordered categorical variable. The model assumes that each successive health quality category is evenly space by treating health quality as continuous. We evaluate whether this approach attenuates the relationship between SWB and health quality and do not find any evidence to suggest this is the case (Williams, 2020; Long \& Freese, 2006; Pasta, 2009).

3. The empirical estimates from Equations (3) and (4) are applied to the theoretical models expressed in Equations (1) and (2). As a result we are able to calculate $C S_{w \rightarrow b}$ and 
$E S_{w \rightarrow b}$ from the following two equations:

$$
\begin{aligned}
& S_{w} \equiv \alpha_{1} \ln \left(m_{w}\right)+\rho_{w} R_{w}=\alpha_{1} \ln \left(m_{b}-C S_{w \rightarrow b}\right)+\rho_{b} R_{b}+\varphi_{b} Q_{b} \\
& S_{b} \equiv \alpha_{1} \ln \left(m_{w}+E S_{w \rightarrow b}\right)+\rho_{w} R_{w}=\alpha_{1} \ln \left(m_{b}\right)+\rho_{b} R_{b}+\varphi_{b} Q_{b}
\end{aligned}
$$

4. We recognize that the paradigm of intersectionality challenges scholars to simultaneously account for overlapping identities (Hancock, 2007). Our data constrain us from analyzing race-gendered differences, but the results are illuminating, nonetheless.

5. The official purpose of the bill: "To address the fundamental injustice, cruelty, brutality, and inhumanity of slavery in the United States and the 13 American colonies between 1619 and 1865 and to establish a commission to study and consider a national apology and proposal for reparations for the institution of slavery, its subsequent de jure and de facto racial and economic discrimination against African-Americans, and the impact of these forces on living African-Americans, to make recommendations to the Congress on appropriate remedies, and for other purposes." Other political representatives have continued to introduce this bill since Conyers' resignation (Congress.gov).

\section{References}

Acevedo-Garcia, D., Osypuk, T. L., McArdle, N., \& Williams, D. R. (2008). Toward a policyrelevant analysis of geographic and racial/ethnic disparities in child health. Health Affairs, 27(2), 321-333. https://doi.org/10.1377/hlthaff.27.2.321

Alexander, M. (2010). The New Jim crow: Mass incarceration in the Age of colorblindness. The New Press.

Benjamin, D. J., Heffetz, O., Kimball, M. S., \& Rees-Jones, A. (2014). Can marginal rates of substitution Be inferred from happiness data? Evidence from residency choices. The American Economic Review, 104(1), 3498-3528. https://doi.org/10.1257/aer.104.11.3498

Bonilla-Silva, E. (1997). Rethinking racism: Toward a structural interpretation. American Sociological Review, 62(3), 465-480. https://doi.org/10.2307/2657316

Bureau of Labor Statistics (2014). Table E-16. Unemployment rates by age, sex, race, and hispanic or latino ethnicity. In Labor force statistics from the current population survey. United States Department of Labor.

Center on Society and Health (2015). "Mapping Life Expectancy." Available at: http://www. societyhealth.vcu.edu/work/the-projects/mapping-life-expectancy.html (accessed July 1).

Chapman, J., Dean, M., Ortoleva, P., Snowberg, E., \& Camerer, C. (2017). "Willingness to Pay and Willingness to Accept are Probably Less Correlated Than You Think." National Bureau of Economic Research (No. w23954).

Chetty, R., Henden, N., Jones, M. R., \& Porter, S. R. (2018). "Race and Economic Opportunity in the United States: An Intergenerational Perspective." National Bureau of Economic Research (No. w24441).

Coates, T.-N. (2014). The case for reparations. The Atlantic, 313(5), 54-71. https://doi.org/10. 7312/asme16959-003

Cohen, C. J. (1999). The boundaries of blackness: AIDS and the breakdown of black politics. University of Chicago Press.

Cohen, P. (2014). "For Recent Black College Graduates, a Tougher Road." New York Times, December 25, Business.

Cottom, T. M. (2017). Lower ed: The troubling rise of for-profit colleges in the new economy. The New Press. 
Coursey, D. L., Hovis, J. L., \& Schulze, W. D. (1987). The disparity between willingness to accept and willingness to pay measures of value. The Quarterly Journal of Economics, 102(3), 679-690. https://doi.org/10.2307/1884223

Crenshaw, K. (1989). Demarginalizing the intersection of race and sex: A black feminist critique of antidiscrimination doctrine, feminist theory and antiracist politics. University of Chicago Legal Forum, 1(8), 139-167. https://doi.org/10.4324/9780429500480

Crenshaw, K. W. (1991). Mapping the margins: Intersectionality, identity politics, and violence against women of color. Stanford law Review, 43(6), 1241-1299. https://doi.org/10.2307/ 1229039

Crenshaw, K. W. (2006). "The Urgency of Intersectionality." In TED, edited by TED. https:// www.youtube.com/watch? $\mathrm{v}=$ akOe5-UsQ2o\&t=495s.

Cummings, J. L. (2020). Assessing US racial and gender differences in happiness, 1972-2016: An intersectional approach. Journal of Happiness Studies, 21(2), 709-732. https://doi.org/ 10.1007/s10902-019-00103-z

Cykert, S., Dilworth-Anderson, P., Monroe, M. H., Walker, P., McGuire, F. R., Corbie-Smith, G., Edwards, L. J., \& Bunton, A. J. (2010). Factors associated with decisions to undergo surgery among patients with newly diagnosed early-stage lung cancer. JAMA, 303(23), 23682376. https://doi.org/10.1001/jama.2010.793

Daly, A., Hess, S., \& de Jong, G. (2012). Calculating errors for measures derived from choice modeling estimates. Transportation Research Part B: Methodological, 46(2), 333-341. https://doi.org/10.1016/j.trb.2011.10.008

Darity, W. A. (2008). Forty acres and a mule in the 21st century. Social Science Quarterly, 89(3), 656-664. https://doi.org/10.1111/j.1540-6237.2008.00555.x

Darity, W. A., \& Frank, D. (2003). The economics of reparations. The American Economic Review, 93(2), 326-329. http://www.jstor.org/stable/3132248

Darity, W., \& Mullen, K. (2020). Black reparations and the racial wealth gap. The Bookings Institution. https://www.brookings.edu/blog/up-front/2020/06/15/black-reparations-andthe-racial-wealth-gap/

Dawson, M. C., \& Popoff, R. (2004). Reparations: Justice and greed in black and white. Du Bois Review: Social Science Research on Race, 1(1), 47-91. https://doi.org/10.1017/ S1742058X04040056

Dressler, W. W., Oths, K. S., \& Gravlee, C. C. (2005). Race and ethnicity in public health research: Models to explain health disparities. Annual Review of Anthropology, 34(1), 231-252. https://doi.org/10.1146/ annurev.anthro.34.081804.120505

Editorial Board (2017). "Colllege Does Not Close Racial Pay Gaps." The New York Times, September 20, 2017.

Eligon, J., \& Gebeloff, R. (2016). "Affluent and Black, and Still Trapped by Segregation." New York Times. Retrieved March 1, 2018, https://www.nytimes.com/2016/08/21/us/ milwaukee-segregation-wealthy-black-families.html.

Feagin, J. (2013). Systemic racism: A theory of oppression. Routledge.

Ferrer-i-Carbonell, A., \& Frijters, P. (2004). How important is methodology for the estimates of the determinants of happiness. The Economic Journal, 114(1), 641-659. https://doi.org/ 10.1111/j.1468-0297.2004.00235.x

Ferrer-i-Carbonell, A., \& van Praag, B. M. S. (2002). The subjective costs of health losses Due to chronic diseases. An alternative model for monetary appraisal. Health Economics, 11(1), 709-722. https://doi.org/10.1002/hec.696

Finkelstein, A., Luttmer, E. F. P., \& Notowidigdo, M. J. (2013). What good is wealth without health? The effect of health on marginal utility of consumption. Journal 
European Economic Association, 11(S1), 221-258. https://doi.org/10.1111/j.15424774.2012

Fitzpatrick, K., \& LaGory, M. (2002). Unhealthy places: The ecology of risk in the urban landscape. Routledge.

Freeman, R. (2003). The measurement of environmental and resource values: Theory and methods. Routledge.

Gong, J., Lu, Y., \& Song, H. (2018). The effect of teacher gender on students' academic and noncognitive outcomes. Journal of Labor Economics, 36(3), 743-778.

Greene, W. H. (2012). Econometric analysis (7th ed.). Pearson.

Greene, W. H., \& Seaks, T. G. (1991). The restricted least squares estimator: A pedagogical note. The Review of Economics and Statistics, 73(3), 563-567. https://doi.org/10.2307/ 2109587

Hacker, A. (1992). Two nations: Black and white, separate, hostile, unequal. Scribner.

Hamilton, D., Darity, W., Price, A., Sridharan, V., \& Tippett, R. (2015). Umbrellas don't make it rain: Why studying and working hard isn't enough for black Americans. Insight Center for Community Economic Development.

Hancock, A.-M. (2007). When multiplication doesn't equal quick addition: Examining intersectionality as a research paradigm. Perspectives on Politics, 5(1), 63-79. https://doi.org/10. 1017/S1537592707070065

Hanemann, W. M. (1991). Willingness to pay and willingness to accept: How much can they differ? The American Economic Review, 81(3), 635-647. https://www.jstor.org/stable/ 2006525

Hannah-Jones, N. (2014). Segregation Now: Investigating america's racial divide. ProPublica.

Hasnain-Wynia, R., Baker, D. W., Nerenz, D., Feinglass, J., Beal, A. C., Landrum, M. B., Behal, R., \& Weissman, J. S. (2007). Disparities in health care are driven by where minority patients seek care: Examination of the hospital quality alliance measures. Archives of Internal Medicine, 167(12), 1233-1239. https://doi.org/10.1001/archinte.167.12.1233

Hausman, J. A. (1981). Exact consumer's surplus and deadweight loss. The American Economic Review, 71(4), 662-676. https://www.jstor.org/stable/1806188

Hegewisch, A., \& Williams-Baron, E. (2017). The gender wage Gap: 2016; earnings differences by gender, race, and ethnicity. Institute for Women's Policy Research.

Hicks, J. R. (1943). The four consumer's surpluses. Review of Economic Studies, 11(1), 31-41. https://doi.org/10.2307/2967517

Hoogerheide, L., Block, J. H., \& Thurik, R. (2012). Family background variables as instruments for education in income regressions: A bayesian analysis. Economics of Education Review, $31(5), 515-523$.

Hout, M. (2004). Getting the most Out of the GSS income measures. Survey Research Center Working Paper.

Hughes, M., \& Thomas, M. E. (1998). The continuing significance of race revisited: A study of race, class, and quality of life in america, 1972 to 1996. American Sociological Review, 63(6), 785795. https://doi.org/10.2307/2657501

Joffe, C., \& Parker, W. J. (2012). Race, reproductive politics and reproductive health care in the contemporary United States. Contraception, 86(1), 1-3. https://doi.org/10.1016/j. contraception.2012.03.009

Johnson, M. P., \& Sell, R. R. (1976). The cost of being black: A 1970 update. American Journal of Sociology, 82(1), 183-190. https://www.jstor.org/stable/2777466

Kahneman, D., \& Tversky, A. (1979). Prospect theory: An analysis of decision under risk. Econometrica, 47(2), 363-391. https://doi.org/10.1142/9789814417358_0006 
Kleibergen, F., \& Paap, R. (2006). Generalized reduced rank tests using the singular value decomposition. Journal of Econometrics, 133(1), 97-126.

Lankford, H. R. (1988). Measuring welfare changes in settings with imposed quantities. Journal of Environmental Economics and Management, 15(1), 45-63. https://doi.org/10.1016/00950696(88)90027-7

Lean In (2019). “The Black Women's Pay Gap by the Numbers.” Retrieved July 18, https:// leanin.org/data-about-the-gender-pay-gap-for-black-women.

Lebron, C. J. (2017). The making of black lives matter: A brief history of an idea. Oxford University Press.

Levinson, A. (2012). Valuing public goods using happiness data: The case of Air quality. Journal of Public Economic, 96(1), 869-880. https://doi.org/10.1016/j.jpubeco.2012.06.007

Long, J. S., \& Freese, J. (2006). Regression models for categorical dependent variables using stata (Vol. 7). Stata Press.

Lopez Bunyasi, T., \& Smith, C. W. (2019a). Do all black lives matter to black people? Respectability politics and the limitations of linked fate. Journal of Race, Ethnicity and Politics, 4(1), 180-215. https://doi.org/10.1017/rep.2018.33

Lopez Bunyasi, T., \& Smith, C. W. (2019b). Stay woke: A people's guide to making all black lives matter. NYU Press.

Luechinger, S. (2009). Valuing air quality using the life satisfaction approach. The Economic Journal, 119(536), 483-515. https://doi.org/10.1111/j.1468-0297.2008.02241.x

MacLeod, W. B., \& Urquiola, M. (2015). "Reputation and school competition." American Economic Review, 105(11), 3471-3488.

Malat, J., Timberlake, J. M., \& Williams, D. R. (2011). The effects of Obama's political success on the self-rated health of blacks, hispanics, and whites. Ethnicity \& Disease, 21(3), 349-355. PMID: 21942169

Matthew, D. B., Rodrigue, E., \& Reeves, R. V. (2016). Time for justice: Tackling race inequalities in health and housing. Brookings.

Mazzocco, P. J., Brock, T. C., Brock, G. J., Olson, K. R., \& Banaji, M. R. (2006). The cost of being black: White Americans' perceptions and the question of reparations. Du Bois Review: Social Science Research on Race, 3(2), 261-297. https://doi.org/10.1017/S1742058X06060206

McIntosh, P. (1998 [1989]). White privilege: Unpacking the invisible knapsack. In P. S. Rothenberg (Ed.), Race, class, and gender in the United States: An integrated study (pp. 165-169). Worth Publishers.

Mills, C. (2007). White ignorance. Race and epistemologies of ignorance, 247(1), 26-31. https:// doi.org/10.1093/acprof:oso/9780190245412.003.0004

Mueller, J. C. (2017). Producing colorblindness: Everyday mechanisms of white ignorance. Social Problems, 64(2), 219-238. https://doi.org/10.1093/socpro/spw061

Oliver, M., \& Shapiro, T. (1995). Black wealth/white wealth: A new perspective on racial inequality. Routledge.

Omi, M., \& Winant, H. (1994). Racial formation in the United States: From the 1960s to the 1990 s (2nd ed.). Routledge.

Pager, D. (2007). Marked: Race, crime, and finding work in an Era of mass incarceration. University of Chicago Press.

Pager, D., \& Shepherd, H. (2008). The sociology of discrimination: Racial discrimination in employment, housing, credit, and consumer markets. Annu. Rev. Sociol, 34(1), 181-209. https://doi.org/10.1146/annurev.soc.33.040406.131740

Pasta, D. J. (2009). “Learning to be Discrete: Continuous vs. Categorical Predictors." SAS Paper: 248-2009. 
Patten, E. (2016). Racial, gender wage gap persist in U.S. Despite some progress. Pew Research Center. https://www.pewresearch.org/fact-tank/2016/07/01/racial-gender-wage-gaps-persistin-u-s-despite-some-progress/

Perez-Truglia, R. (2015). A samuelsonian validation test for happiness data. Journal of Economic Psychology, 49(1), 74-83. https://doi.org/10.1016/j.joep.2015.05.002

Powdthavee, N. (2010). How much does money really matter? Estimating the causal effects of income on happiness. Empirical Economics, 39(1), 77-92. https://doi.org/10.1007/s00181009-0295-5

Ranson, R., \& Sutch, R. (1990). Who pays for slavery? In R. F. America (Ed.), The wealth of races: The present value of benefits from past injustices (pp. 107-123). Greenwood Press.

Royster, D. A. (2003). Race and the invisible hand: How white networks exclude black men from blue-collar jobs. Univ of California Press.

Seamster, L. (2019). Black debt, white debt. Contexts, 18(1), 30-35. https://doi.org/10.1177/ 1536504219830674

Shapiro, T. M. (2004). The hidden cost of being african American: How wealth perpetuates inequality. Oxford University Press.

Shogren, J. F., Shin, S. Y., Hayes, D. J., \& Kliebenstein, J. B. (1994). Resolving differences in willingness to pay and willingness to accept. The American Economic Review, 84(1), 255-270. https://www.jstor.org/stable/2117981

Siegel, P. M. (1965). On the cost of being a Negro. Sociological Inquiry, 35(1), 41-57. https:// doi.org/10.1111/j.1475-682X.1965.tb00589.x

Simon, S. (2016). Rising U.S. Mortality rate for mothers is highest in texas. National Public Radio: Weekend Edition Saturday.

Suits, D. B. (1984). Dummy variables: Mechanics V. Interpretation. The Review of Economic Statistics, 66(1), 177-180. https://doi.org/10.2307/1924713

Taylor, K.-Y. (2016). From \#BlackLivesMatter to black liberation. Haymarket Books.

Tucker, M. J., Berg, C. J., Callaghan, W. M., \& Hsia, J. (2007). The black-white disparity in pregnancy-related mortality from 5 conditions: Differences in prevalence and case-fatality rates. American Journal of Public Health, 97(2), 247-251. https://oi.org/10.2105/AJPH. 2005.072975

Veenhoven, R. (1996). Happy life-expectancy. Social Indicators Research, 39(1), 1-58. https:// doi.org/10.1007/BF00300831

Welsch, H. (2007). Environmental welfare analysis: A life satisfaction approach. Ecological Economics, 62(1), 544-551. https://doi.org/10.1016/j.ecolecon.2006.07.017

Williams, R. A. (2020). Ordinal independent variables. In: P. Atkinson, S. Delamont, A. Cernat, J. W. Sakshaug, \& R. A. Williams (Eds.). SAGE Research Methods Foundations. https://doi. org/10.4135/9781526421036938055

Williams, D. R., \& Mohammed, S. A. (2009). Discrimination and racial disparities in health: Evidence and needed research. Journal of Behavioral Medicine, 32(1), 20-47. https://doi. org/10.1007/s10865-008-9185-0

Willig, R. D. (1976). Consumer's surplus without apology. The American Economic Review, 66(4), 589-597. http://www.jstor.org/stable/1806699

Yang, Y. (2008). Social inequalities in happiness in the United States, 1972 to 2004: An age-period-cohort analysis. American Sociological Review, 73(2), 204-226. https://doi. org/10.1177/000312240807300202

Zaw, K., Bhattacharya, J., Price, A., Hamilton, D., \& Darity, W.Jr. (2017). Women, race and wealth. Research brief series, 1(1), 1-4. 


\section{Appendix}

\section{Evaluating the IV Approach}

One of the main shortcomings with the SWB valuation approach is that there are few publicly available data sets which include appropriate instruments for income (Powdthavee, 2010). This particular challenge is multiplied given that we attempt to estimate the SWB model across two independent, nationally representative, data sets. In our study we approach this empirical obstacle by instrumenting income with educational attainment measured in discrete units. While we do not find any evidence of education being a weak instrument, we are unable to formally test the exclusion

Table AI. Estimates From the GSS Sample Using 2SLS.

Dependent Variables: Happiness

$\begin{array}{ccc}\text { IV: Education } & \text { IV: Mother's Ed. } & \text { IV: Mother's OCC Prestige } \\ \text { (I) } & \text { (2) } & \text { (3) }\end{array}$

\begin{tabular}{lccc}
\hline Race & & & \\
\hline White & $2.050^{* * *}$ & $2.054^{* * *}$ & $2.049 * * *$ \\
& $(0.037)$ & $(0.014)$ & $(0.021)$ \\
Black & $1.986^{* * *}$ & $2.001 * * *$ & $1.978^{* * *}$ \\
& $(0.029)$ & $(0.022)$ & $(0.037)$ \\
In(Income) & $0.082^{* * *}$ & $0.0723^{*}$ & $0.117^{*}$ \\
& $(0.028)$ & $(0.037)$ & $(0.069)$ \\
Health & $0.193 * * *$ & $0.196^{* * *}$ & $0.188^{* * *}$ \\
& $(0.011)$ & $(0.012)$ & $(0.016)$ \\
Health $\times$ Race & & & -0.0178 \\
Black & -0.005 & -0.00716 & $(0.015)$ \\
& $(0.025)$ & $(0.018)$ & $\checkmark$ \\
Covariates & $\checkmark$ & $\checkmark$ & 35 \\
Weak identification test & & & 6,155 \\
Kleibergen-Paap Wald rk $\mathrm{F}$ & 439 & 8,337 & $-128,255$ \\
No. Observations & 9,030 & $-123,396$ & $(208,231)$ \\
CS: White $\rightarrow$ Black & $-134,116$ & $(243,757)$ & $-44,885^{*}$ \\
& $(235,679)$ & $-44,131$ & $(25,504)$ \\
ES: White $\rightarrow$ Black & $-44,852^{*}$ & $(31,177)$ &
\end{tabular}

Note: Columns I through 3 represents 2SLS estimations from the GSS data using different instruments. Column I presents the results where respondent's education worked as the instrument for income and is not different from the results presented in Table 3. Column 2 presents the results where mother's education was used as the instrumental variable. Finally, Column 3 presents the results where mother's occupational prestige was used the instrumental variable. Covariates include age, gender, marital status, number of children. The table also reports the results from a Kleibergen-Paap weak identification test. Standard errors are reported in parenthesis. The standard errors for CS and ES were estimated using the Delta method. Significance levels are identified as $* * * p<.01$; ** $p<.05 ; * p<. I$. 
restriction criteria. The validity of using education as an instrument relies on the assumption that educational attainment has no effect on SWB other than through its impact on income. In the context of the SWB approach to non-market valuation, educational attainment must have no consumptive value beyond its value received in the labor market, e.g., the economic returns to education.

The literature attempting to empirically disentangle whether or not education is a consumption or an investment good is largely mixed (MacLeod \& Urquiola, 2015). Furthermore, these studies have primarily situated the context of the analysis on school choice. While an argument can be made that there is consumptive value to school choice - a potential reason universities and colleges have heavily invested in lavish amenities (e.g. rock-climbing walls, lazy rivers, etc.) - it is unclear whether or not a degree once earned produces the same or similar consumptive value. We ultimately are unable to point to this literature to articulate a justifiable empirical strategy. However, we attempt to provide insights into the validity of using educational attainment as an instrument, in the SWB context, by focusing our analysis on the GSS data set.

The BRFSS data provides a wealth of information about each respondent's health and, as shown in the descriptive statistics has a large number of observations to power the model. However, the BRFSS is limited in its coverage of socioeconomic characteristics of its respondents, such as occupation, employment duration, and individual income. The GSS, on the other hand, has much fewer observations but cover more details characterizing the socioeconomic situation of its respondents. In this evaluation, we leverage the mother's education and occupation for each respondent as an instrument for income using the GSS data set. Studies have provided evidence for the validity of using family background as an instrument for education and income (Hoogerheide et al., 2012; Gong et al., 2018).

In Table A1, we present our 2SLS estimations using various instrumental variables. The results in Column 1 contain estimates where educational attainment is used as the instrument for income - these are the same results from Table 3 and are shown for comparison. In Column 2 we present the results where the respondent's mother's education attainment is used as the instrument. Finally, in Column 3, we use mother's occupational prestige score as an alternative instrumental variable for income. Additionally, we provide results from a weak identification test as well as the $C S_{w \rightarrow b}$ and $E S_{w \rightarrow b}$ estimates. We do not find evidence to suggest that the instruments explored here are weak or irrelevant. The results also suggest both that the estimated coefficients and welfare measures are similar across each approach. Overall, and to the best of our ability given data limitation, we do not find evidence to invalidate or implicate the integrity of our results.

\section{Changing the Status Quo}

In this section we reevaluate $C S$ and $E S$ with the assumption that being Black, as a race state, is the status quo from which we measure the change in welfare. Theoretically, this positioning of the status quo $\left(C S_{b \rightarrow w}\right.$ and $\left.E S_{b \rightarrow w}\right)$ leads to different interpretations of the same measures. To accommodate this assumption in the empirical model, we use 
the Black racial category as the baseline. However, it is important to note that given the nature of the study, primarily that it is driven by secondary data, we do not expect that the WTP or WTA measures to change in magnitude, only the interpretation. The analysis does not functionally change the empirical model only how the baseline category is defined in the model.

In Table 2A, we present the 2SLS results evaluated from the BRFSS and GSS data sets in columns 2 and 4 . Columns 1 and 3 of Table 2A presents the 2SLS estimates from Table 3. In columns 2 and 4, $C S_{b \rightarrow w}$ and $E S_{b \rightarrow w}$ represents WTP and WTA, respectively. The change in corresponding $C S / E S$ to WTP/WTA designations is shown in the first note of the manuscript (notes section). For instance, $C S_{b \rightarrow w}$ is now interpreted WTP. 


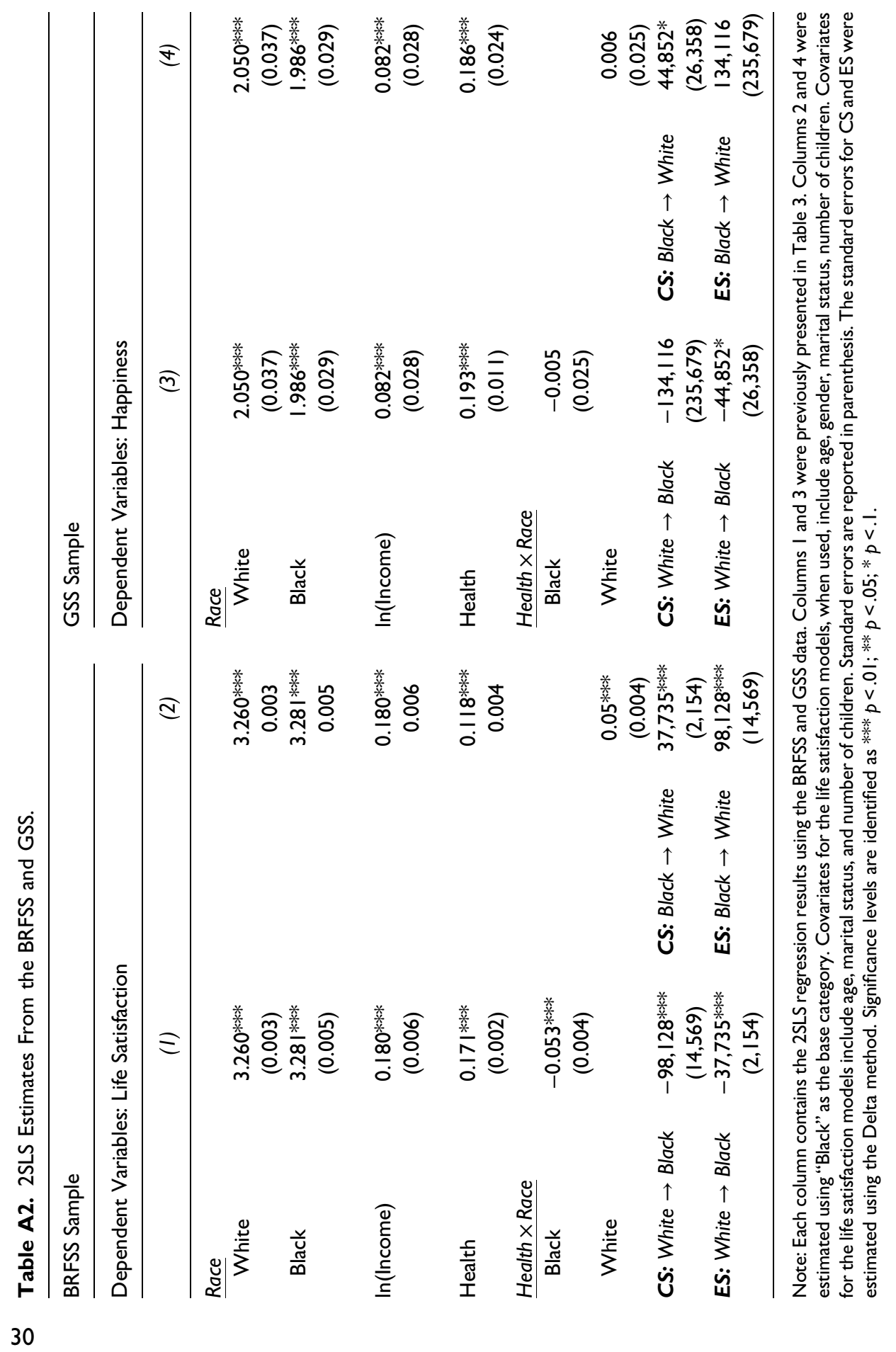

